\title{
Case report: the use of the AWIN welfare assessment protocol to monitor a group of abandoned donkeys
}

\section{Estudo de caso: o uso do protocolo AWIN de avaliação de bem-estar para monitorar um grupo de jumentos abandonados}

\author{
Sharacely de Souza Farias ${ }^{1}$ (D); Mariana Bombo Perozzi Gameiro ${ }^{1}$ (D); Ana Carolina Dierings Montechese ${ }^{1}$; \\ Thiago Bernardino $^{1}$ (i); Chiara Albano de Araujo Oliveira ${ }^{2}$ (i); Adroaldo José Zanella ${ }^{1}$
${ }^{1}$ Universidade de São Paulo, Faculdade de Medicina Veterinária e Zootecnia, Departamento de Medicina Veterinária Preventiva e Saúde Animal, Pirassununga - SP, Brazil Produção Animal, Salvador - BA, Brazil \\ ${ }^{2}$ Universidade Federal da Bahia, Escola de Medicina Veterinária e Zootecnia, Departamento de Medicina Veterinária Preventiva e
}

\begin{abstract}
The objective of this study was to reach a diagnosis of the living conditions of abandoned donkeys kept in a restricted farm area through the assessment of their welfare level utilizing the AWIN protocol as a methodological tool. These animals were supposed to be sent to slaughter, but after the activity was temporarily banned, they were abandoned by traders. The protocol of welfare assessment was associated with general environmental and sanitary conditions. Information regarding the mortality rates was also gathered. According to the welfare assessment results, the living conditions of these animals were acceptable in some areas, despite the insufficient shade and shelter, a 3-month food restriction period, and a mortality rate of over $70 \%$. These results demonstrate that welfare assessment protocols must be adapted to crises and databases for welfare indicators in diverse conditions must be created.
\end{abstract}

Keywords: Asinine. Assessment protocol. Behavioral assessments. Mistreatment. Northeast region.

\section{RESUMO}

O objetivo deste estudo foi formular um diagnóstico das condições de vida de jumentos abandonados mantidos em uma área restrita de uma propriedade através da avaliação de seu nível de bem-estar, utilizando o protocolo AWIN como ferramenta metodológica. Estes animais seriam destinados ao abate, porém, depois da suspensão temporária da atividade, foram abandonados pelos proprietários. O protocolo de avaliação de bem-estar foi associado às condições ambientais e sanitárias gerais. Informações sobre os índices de mortalidade também foram coletadas. De acordo com os resultados da avaliação de bem-estar, as condições de vida destes animais estavam aceitáveis em algumas áreas, embora não houvesse sombreamento e abrigo suficientes, um período de restrição alimentar de 3 meses e um índice de mortalidade acima de $70 \%$. Estes resultados demonstram que protocolos de avaliação de bem-estar devem ser adaptados a situações de crise, e bancos de dados para indicadores de bem-estar em condições diversas devem ser criados.

Palavras-chave: Asininos. Protocolo de avaliação. Mensurações comportamentais. Maus-tratos. Região Nordeste.

\section{Correspondence to:}

Sharacely de Souza Farias

Universidade de São Paulo, Faculdade de Medicina Veterinária

e Zootecnia, Departamento de Medicina Veterinária

Preventiva e Saúde Animal

R. Duque de Caxias, 225, Jardim Elite

CEP: 13635-900, Pirassununga - SP, Brazil

e-mail:shrfarias@usp.br

Received: September 10, 2020

Approved: December 22, 2020
How to cite: Farias SS, Gameiro MBP, Montechese ACD, Bernardino T, Oliveira CAA, Zanella AJ. Case report: the use of the AWIN welfare assessment protocol to monitor a group of abandoned donkeys. Braz J Vet Res Anim Sci. 2021;58(special issue):e174701. https://doi. org/10.11606/issn.1678-4456.bjvras.2021.174701

The world donkey population is approximately 50 million animals and has been decreasing in some regions (Food and Agriculture Organization, 2018), 
possibly due to rural exodus, increased mechanization in agriculture, and the rise in consumption of donkey meat. Another recent contributing factor is the exploitation of donkey skin to cater to the Chinese demands for traditional medicine, represented by the Eijao (Waters, 2019). In Brazil, the total donkey population is greater than 800.000 animals (Food and Agriculture Organization, 2018), and 86.7\% of them are found in the Northeast region (Instituto Brasileiro de Geografia e Estatística, 2017).

In Brazil, donkey slaughter was recently prohibited by legal determinations, resulting in the abandonment of donkeys that were housed extensively in a farm area of 6 ha in the city of Canudos, Bahia. Following the slaughter facility closures, there was an increase in mistreatment and mortality rates of the animals kept on the farm, which worked like a collection point.

The animals assessed in this study were housed in this farm after being captured and transported over distances that reached more than $1500 \mathrm{~km}$, possibly in unsanitary conditions and without nutritional support, leading to their arrival at the farm in a severely debilitated state, which was further aggravated during their housing. As a result, the mortality rate for these animals was extremely high. This situation culminated in the employment of a national task force to investigate the living conditions of the donkeys at the farm.

The objective of this study was to reach a diagnosis of the situation through the assessment of the welfare level of donkeys kept on a farm, which worked as a collection point to bring together animals from various sources to be shipped for slaughter.

This study was approved by the Committee for the Use and Care of Animals in Research (CEUA) of the Federal University of Alagoas (UFAL), under the register no 8696141117. Data collection was carried out between February 14-17, 2019, from 9 am to $2 \mathrm{pm}$ when temperatures reached up to $36^{\circ} \mathrm{C}$. The data was collected by two trained professionals as described in the AWIN protocol for donkey welfare assessment, which utilizes animal-based indicators to assess the welfare levels of animals (Animal Welfare Indicators, 2015) (Figure 1). The protocol was adapted to suit the conditions in the study, by conducting it without restraining or moving the animals.

The mortality rate was reported by the government veterinary team assigned to this situation. There were 800 donkeys on the farm, and as recommended by the protocol guidelines, 58 were assessed. They were chosen at random, from the groups of animals that were closest to the assessors.

The protocol holds as principles and criteria the good feeding (body condition score and water availability), housing (signs of thermal stress), and health (integument alterations, swollen joints, prolapse, hair coat condition, fecal soiling, discharges, abnormal breathing, coughing, and signs of hot branding), as well as appropriate behavior (expression of social behavior, stereotypes, and humananimal interaction) of animals. These correspond to the first level of welfare assessment, according to the AWIN methodology. Additionally, the environmental conditions of the property were also observed, such as the destination of carcasses and the presence of shade.

All collected data were submitted to descriptive analysis in Statistical Analysis System Institute (2013). Data are presented as percentages, the mean and standard deviation of assessments.

The assessed animals were $60.3 \%$ female $(0.60 \pm 0.49)$, and $100 \%$ of males were not castrated (Figure 2). The body condition scores (Figure 3) were considered ideal in $43.1 \%$ of animals $(0.43 \pm 0.49)$ and moderate in $29.3 \%$ $(0.29 \pm 0.45)$. There were no water troughs to be assessed, and the animals drank from natural water sources in which the water was scored as dirty (Figure 4). Thermal stress signs (Figure 5) were not present in $94.83 \%$, of animals $(0.94 \pm 0.22)$.

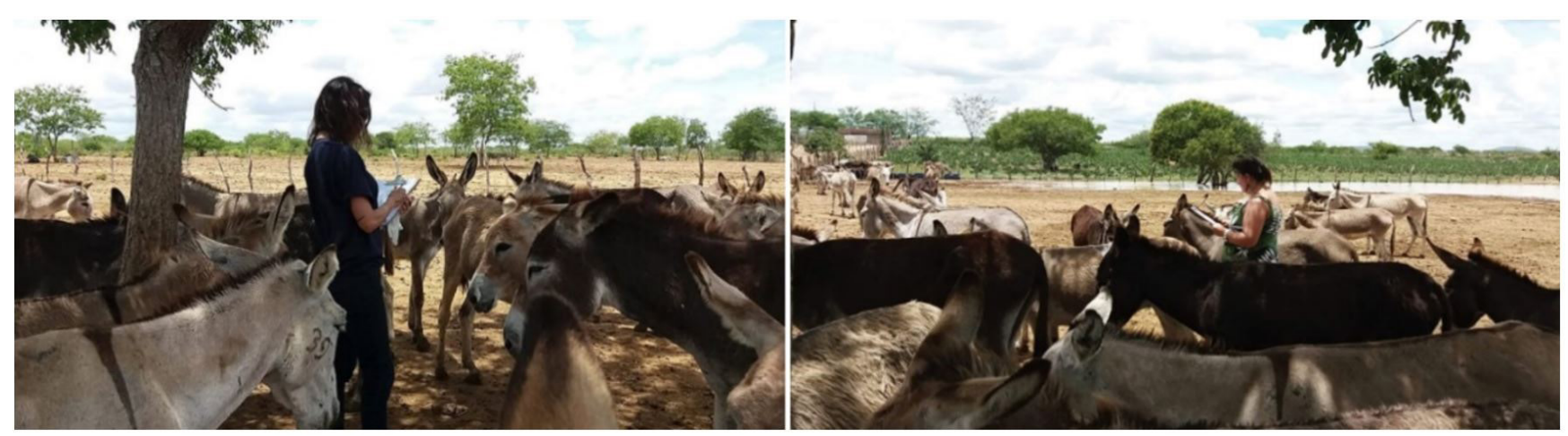

Figure 1 - Trained professionals conducting the welfare assessment on the group of abandoned donkeys utilizing the AWIN protocol as a methodological tool. Source: The authors. 
Regarding integument alterations, $60.3 \%$ presented skin lesions $(0.60 \pm 0,49), 22.41 \%$ presented alopecia $(0.22 \pm 0.42)$ and $13.79 \%$ presented deep wounds $(0.13 \pm 0.34)$. Swollen joints were not found in $84.48 \%$ of animals $(0.84 \pm 0.36)$, and $87.93 \%$ showed no signs of prolapse $(0.87 \pm 0.32)$ (Figure 6).

The coat condition was considered healthy in $81 \%$ of animals $(0.81 \pm 0.39)$. Fecal soiling was not found in $87.93 \%$ $(0.87 \pm 0.32)$. Abnormal breathing was absent from $94.83 \%$ of animals (0.94 \pm 0.22 ), and coughing was absent from $100 \%$ (Figure 7 ). Ocular discharge was absent in $84.48 \%$ of animals ( $0.84 \pm 0.36$ ), nasal discharge was absent in $94.83 \%$ $(0.94 \pm 0.22)$ and $89.66 \%$ showed no signs of vulvar or penis discharges $(0.89 \pm 0.30)$ (Figure 8$)$. Signs of hot iron branding were not found in $87.93 \%(0.87 \pm 0.32)$ (Figure 9$)$.

Based on the behavioral observations (Figure 10), we noted that $89.6 \%$ of donkeys were sociable within their group $(0.89 \pm 0.30), 96.55 \%$ showed no signs of stereotypes $(0.96 \pm 0.18), 55.2 \%$ usually did not avoid human interaction $(0.55 \pm 0.50), 58.6 \%$ stood still in response to human movement $(0.58 \pm 0.49)$ and $55.2 \%$ showed no alterations in tail position, even when parallel to a person $(0.55 \pm 0.50)$.

These results can be partially explained by the sample of animals assessed: the ones who could be assessed by researchers were closest to humans and showed more social behaviors, while feral or "less sociable" donkeys hid and could not be reached. In this sense, it was not possible to assess a large number of animals, as they fled in small groups to distant areas of the farm. It is well-known that donkeys are gregarious animals, adapted to living in small groups (Rudman, 1998), and due to their prey condition, when frightened, they present natural "fight or flight" responses (Burden \& Thiemann, 2015).

The mortality rate for the animals between their arrival at the farm and the time of assessment was over $70 \%$. On the farm, there was little shade available, and the animals could only drink from two natural water sources, exposed to the sun. The water was dirty and there were many carcasses scattered in the surroundings, which could lead to contamination and intoxication of animals (Figure 11).

Based on these results, the welfare assessment protocol underestimated the extremely poor welfare conditions of the animals. The unacceptable mortality rates reported for the animals and the environmental conditions of the farm were not part of the AWIN protocol. It is important to note that protocols for welfare assessment indicate risks of welfare issues, and not a complete picture of the animal's welfare at the time (Rousing et al., 2001).

The high resilience and adaptability of donkeys (Davis, 2019) combined with the natural social isolation behavior

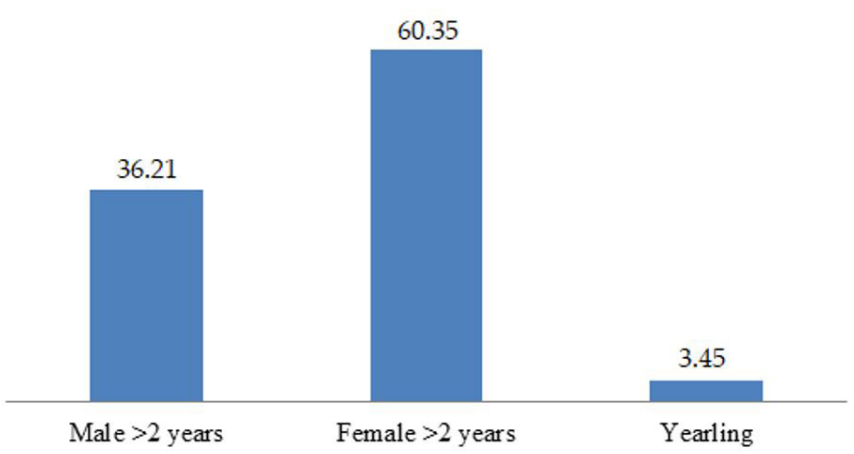

Figure 2 - Percentages of males older than 2 years, females older than 2 years, and yearlings (animals of both sexes aged between 1 and 2 years) in the group of abandoned donkeys at the farm utilizing the AWIN protocol as a methodological tool.

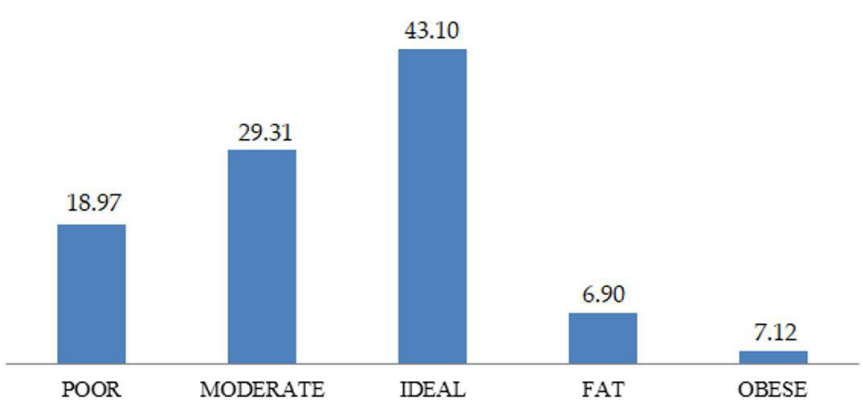

Figure 3 - Percentages of animals in each category of the Body Condition Score scale in the group of abandoned donkeys at the farm utilizing the AWIN protocol as a methodological tool.

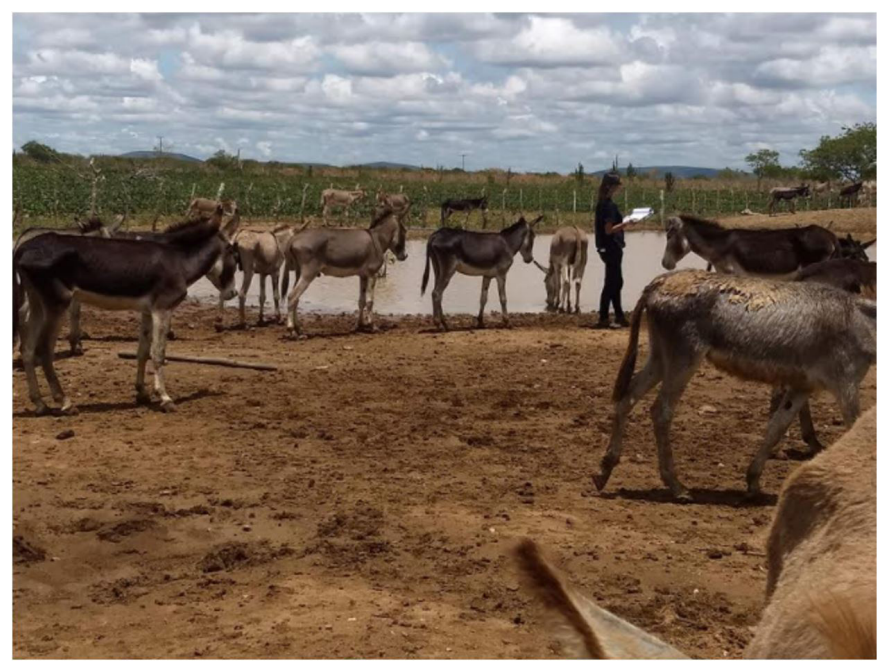

Figure 4 - One of the natural water sources from where the abandoned donkeys drank at the farm, as part of the water availability assessment utilizing the AWIN protocol as a methodological tool.

of sick and threatened animals (Hart \& Hart, 2019), may have generated the assessment of only the strongest and best-adapted individuals, as well as those with better humananimal relationships, which remained close to the assessors. 


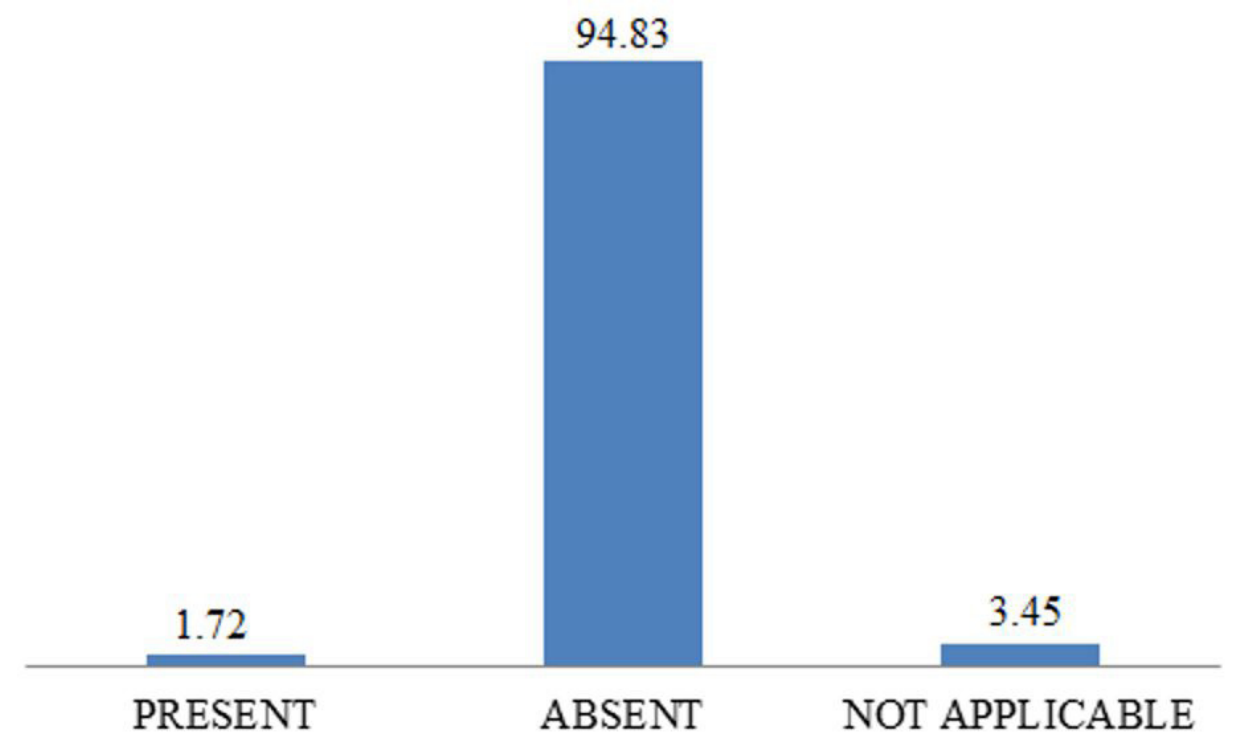

Figure 5 - Percentages of animals showing signs of thermal stress in the group of abandoned donkeys at the farm utilizing the AWIN protocol as a methodological tool.

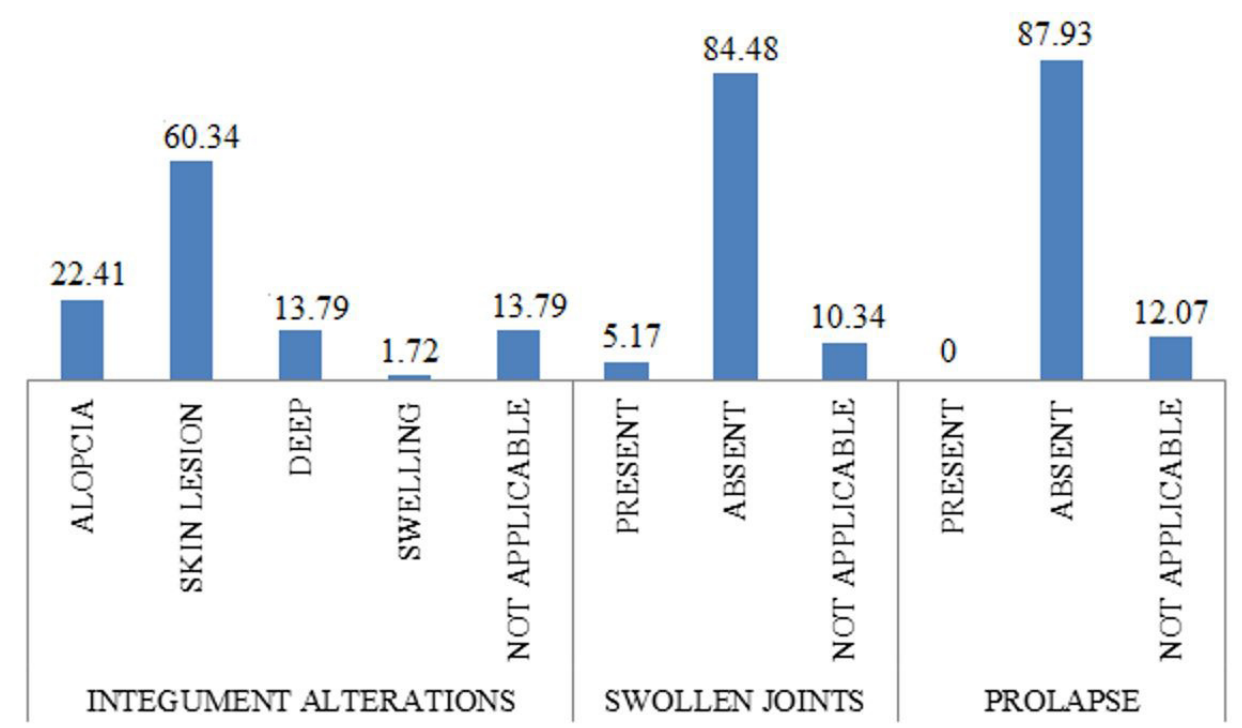

Figure 6 - Percentages of animals showing signs of injuries in the group of abandoned donkeys at the farm utilizing the AWIN protocol as a methodological tool.

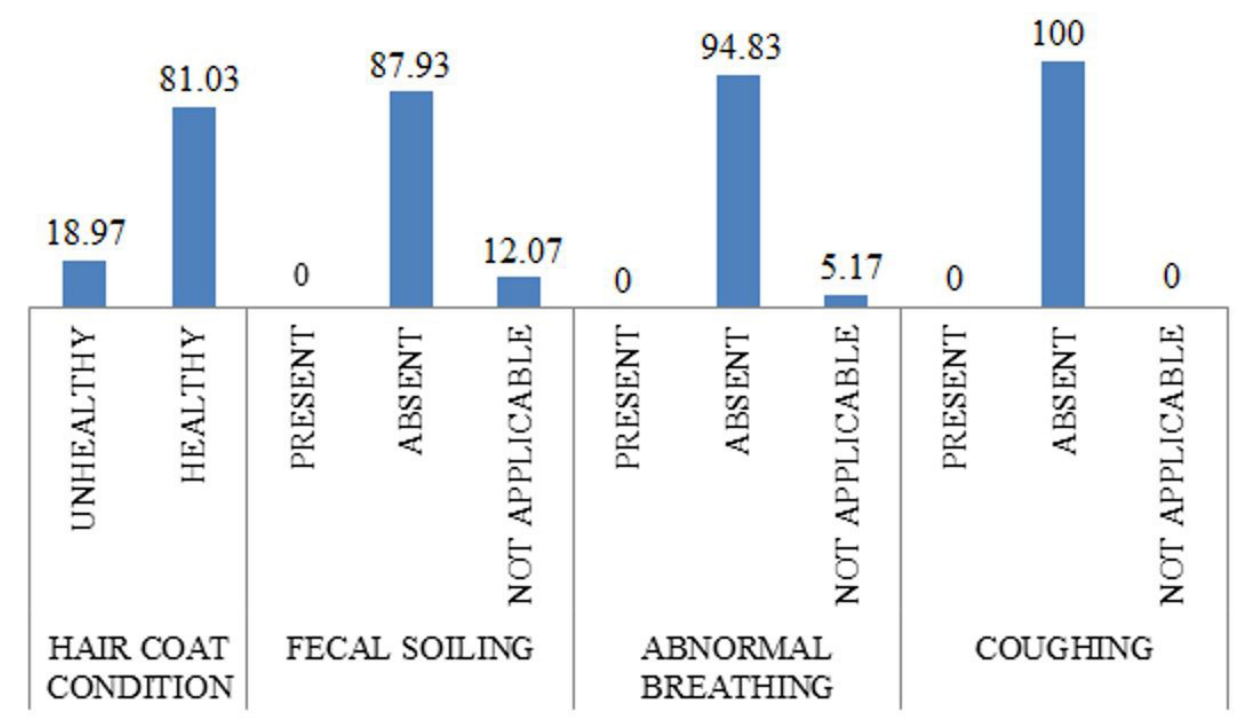

Figure 7 - Percentages of animals in each category of hair coat condition and showing signs of fecal soiling, abnormal breathing, and coughing in the group of abandoned donkeys at the farm utilizing the AWIN protocol as a methodological tool. 


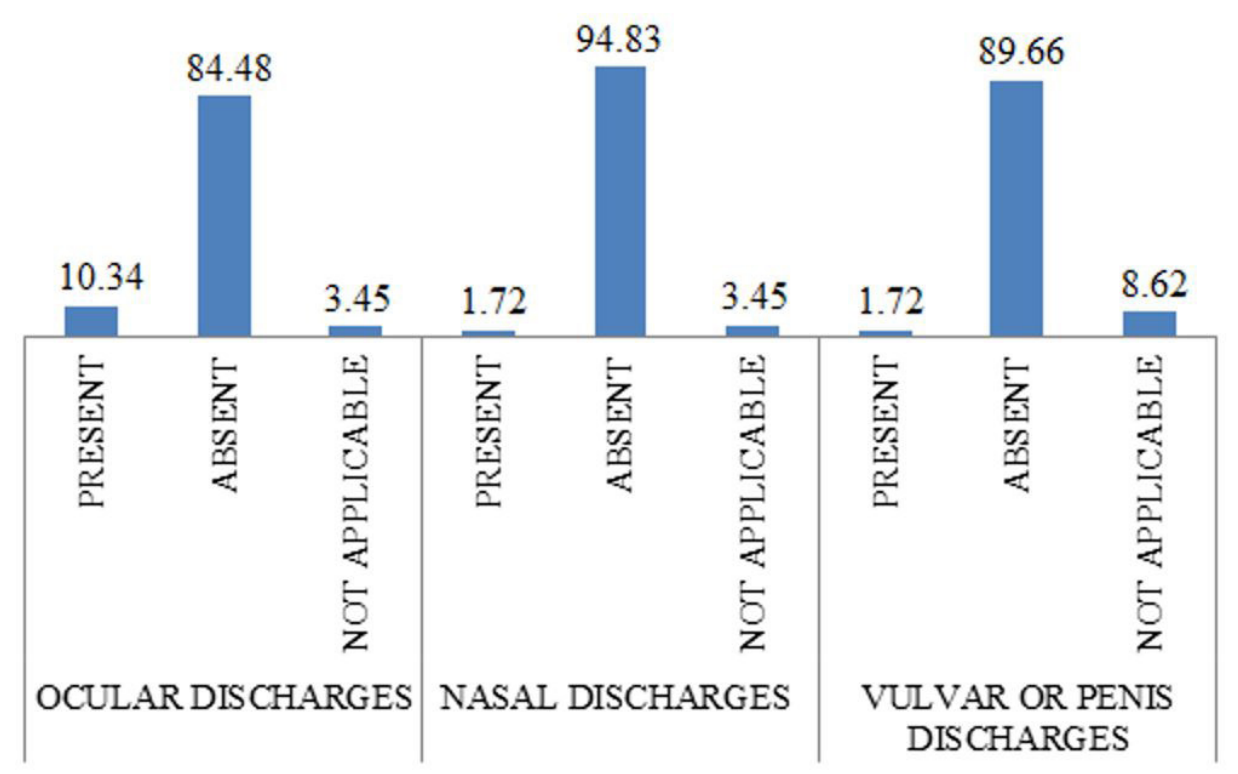

Figure 8 - Percentages of animals showing signs of ocular, nasal, and vulvar or penis discharges in the group of abandoned donkeys at the farm utilizing the AWIN protocol as a methodological tool.

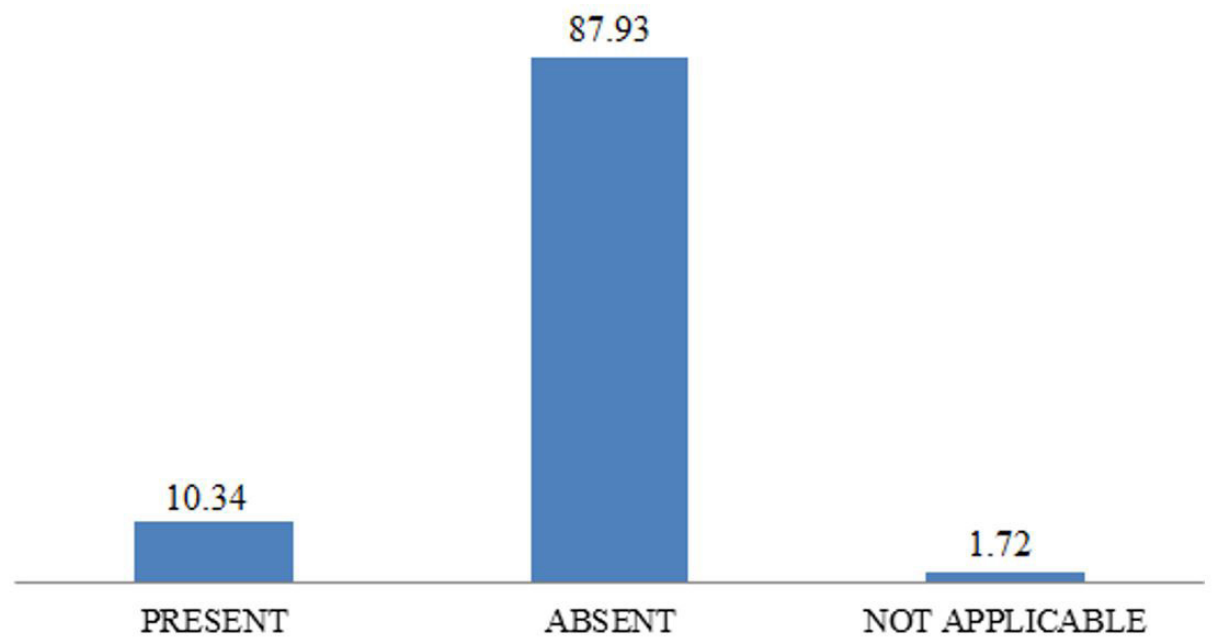

Figure 9 - Percentages of animals showing signs of hot iron branding in the group of abandoned donkeys at the farm utilizing the AWIN protocol as a methodological tool.

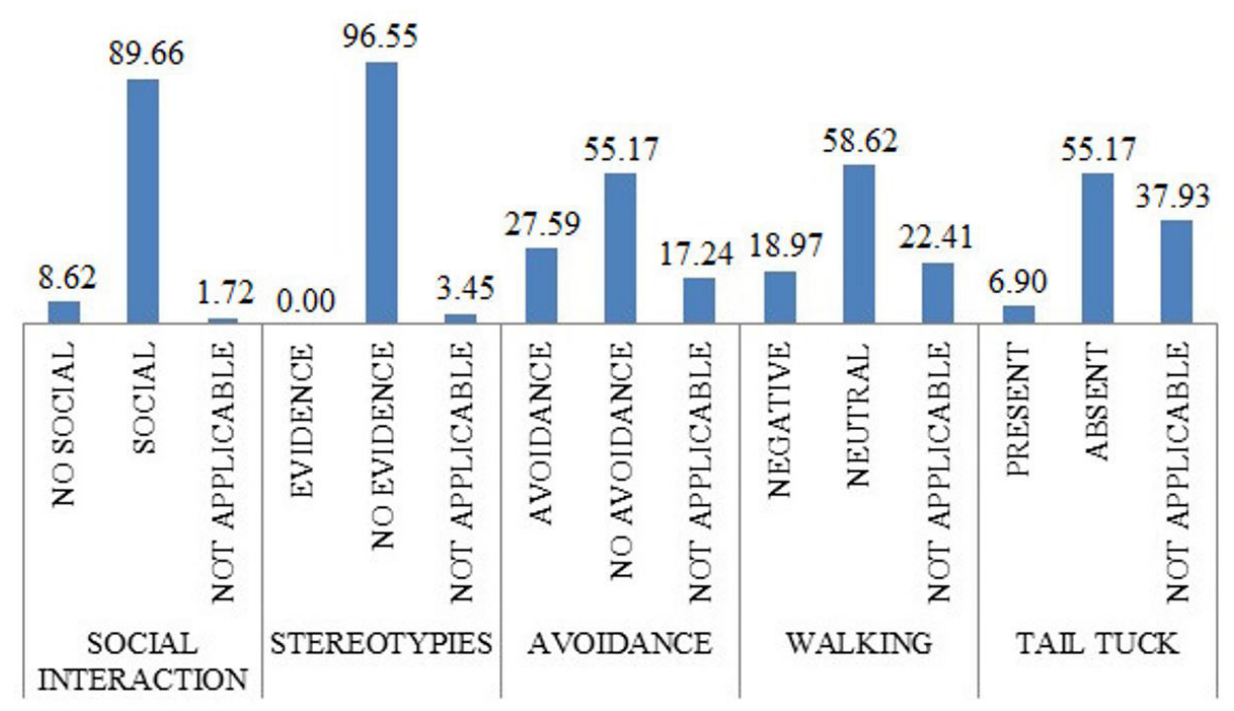

Figure 10 - Percentages of animals performing social interaction, stereotypes, and reactions to human-animal relationship tests (avoidance, walking, and tail tuck) in the group of abandoned donkeys at the farm utilizing the AWIN protocol as a methodological tool. 


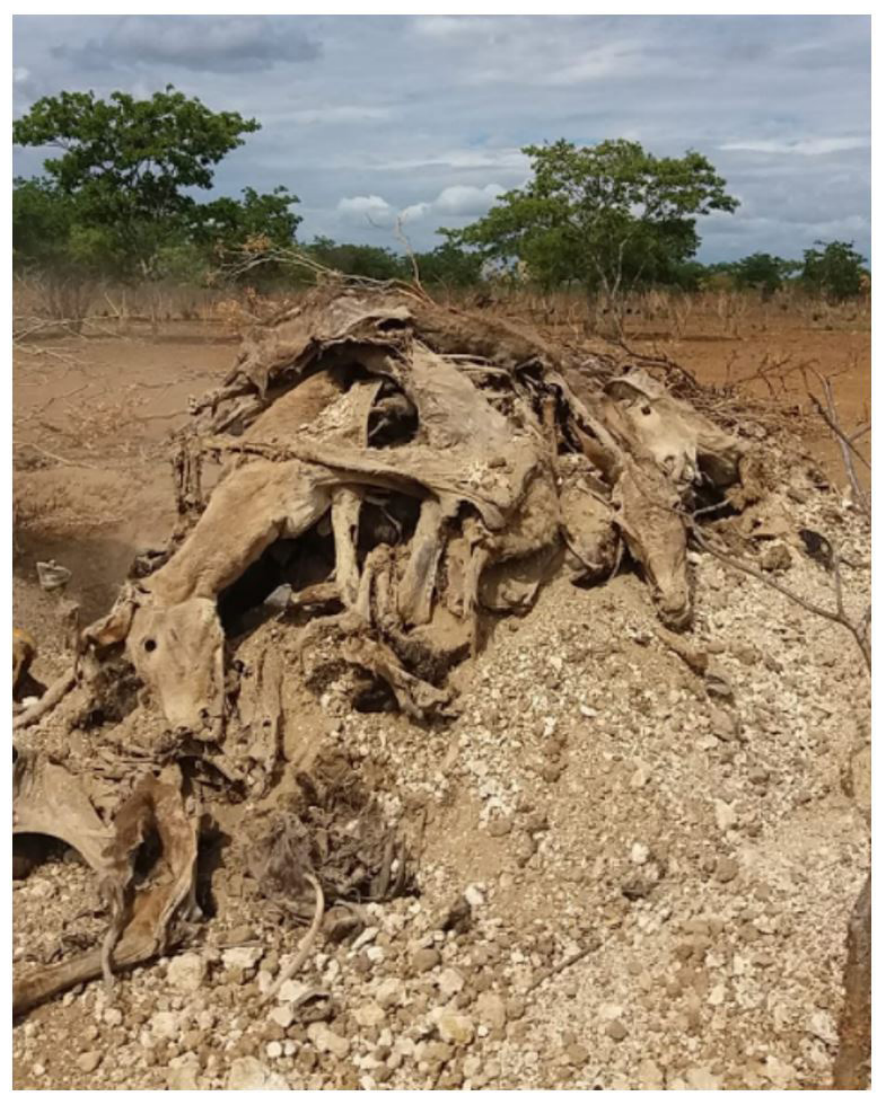

Figure 11 - Presence of carcasses among the abandoned donkeys in the farm in Canudos, BA, as part of the additional environmental conditions assessment conducted in the study. Source: The authors.

The high mortality rate could be explained by possible improper practices in their capture, transport, and the precarious living conditions on the farm. Little is known about the effects of transportation in donkeys (Fazio et al., 2013), but it is well reported as a stressful event for horses, which may lead to serious health disorders and death (Padalino et al., 2016).

The nutritional and environmental conditions on the farm may also have augmented mortality rates. It is known that donkeys are hindgut fermenters and require 1.3-1.8\% of their body weight ingested as dry matter daily (Liu et al., 2020). Although they are highly tolerant of thirst, their daily water intake must be proportional to the ambient

\section{Conflict of Interest}

The authors whose names are listed in this publication have no conflict of interest or financial or non-financial interest in the content discussed in this manuscript.

\section{References}

Animal Welfare Indicators - AWIN. AWIN welfare assessment protocol for donkeys. UK; 2015. http://dx.doi.org/10.13130/ AWIN_donkeys_2015. temperature and humidity, as well as their reproductive stage (Burden \& Thiemann, 2015). Shade and shelter also were not sufficiently provided on the farm. Although the skin of donkeys is suited to direct sunlight and extreme heat (Knottenbelt, 2019), excessive light exposure may cause phototoxicity in equids (Williams \& Barrif, 2011).

The lack of sanitary control, with no clinical evaluation, quarantine for sick animals, and removal of feces or carcasses from the pasture may also lead to various infections and parasite infestations to spread in the studied farm (Knottenbelt, 2019). Very few important requirements to maintain the health and welfare of the animals were met during the three months that they lived in the property before the welfare assessment. This may have generated a refusal for food and water, placing their health at further risk with the development of hyperlipemia, which may have contributed to their high mortality (Burden \& Thiemann, 2015).

This data suggests the importance of conducting welfare assessments in crises, together with clinical veterinarian examinations. Examinations to assure the sanitary and nutritional conditions of animals must be collected before, during, and after their capture, transportation, and housing in the collection farms that function almost as warehouses. Some welfare protocols already include other indirect measurements, such as assessments of resources and questionnaires for farm owners (Pritchard et al., 2005), which could help to build a more complete picture of the situation.

Based on our results, we observed that the limited number of donkeys assessed in this period were in acceptable welfare conditions in all parameters but water quality, based exclusively on the AWIN protocol. However, due to various welfare challenges and their extremely poor overall condition, many animals did die right before the study was conducted. This demonstrates the need for adaptation of welfare protocols to crises, and refinement of welfare assessment techniques. It is also crucial to generate a database for donkey welfare worldwide so that a solid repertoire can be created regarding adequate welfare for diverse situations.

\section{Ethics Statement}

The current study was conducted after the review and approval carried under the protocol 21/2019 issued by the Universidade Federal de Alagoas.

Burden F, Thiemann A. Donkeys are different. J Equine Vet Sci. 2015;35(5):376-82. http://dx.doi.org/10.1016/j. jevs.2015.03.005. 
Davis E. Donkey and mule welfare. Vet Clin North Am Equine Pract. 2019;35(3):481-91. http://dx.doi.org/10.1016/j. cveq.2019.08.005. PMid:31672200.

Food and Agriculture Organization - FAO. Statistics division FAOSTAT [Internet]. Rome: FAO; 2018 [cited 2020 Aug 3]. Available from: http://www.fao.org/faostat/en/\#data/QA

Fazio E, Medica P, Cravana C, Aveni F, Ferlazzo A. Comparative endocrinological responses to short transportation of Equidae (Equus asinus and Equus caballus). Anim Sci J. 2013;84(3):258-63. http://dx.doi.org/10.1111/j.17400929.2012.01065.x. PMid:23480707.

Hart BL, Hart L. Encyclopedia of animal behavior. 2nd ed. Amsterdam: Elsevier Academic Press; 2019. Chapter, Sickness behavior in animals: implications for health and wellness; p. 171-5.

Instituto Brasileiro de Geografia e Estatística - IBGE. Censo agropecuário: pesquisa pecuária municipal. Rio de Janeiro: IBGE; 2017.

Knottenbelt DC. Skin disorders of the donkey and mule. Vet Clin North Am Equine Pract. 2019;35(3):493-514. http:// dx.doi.org/10.1016/j.cveq.2019.08.006. PMid:31672201.

Liu L, Zhou X, Yang H, Chen R. Effect of dietary forage/ concentrate ratio on nutrient digestion and energy and protein metabolism in adult donkeys. Animals. 2020;10(6):1025. http://dx.doi.org/10.3390/ani10061025. PMid:32545612.

Padalino B, Raidal SL, Hall E, Knight P, Celi P, Jeffcott L, Muscatello G. Survey of horse transportation in Australia: issues and practices. Aust Vet J. 2016;94(10):349-57. http:// dx.doi.org/10.1111/avj.12486. PMid:27671078.

Pritchard JC, Lindberg AC, Main DCJ, Whay HR. Assessment of the welfare of working horses, mules and donkeys, using health and behaviour parameters. Prev Vet Med. 2005;69(3-4):265-83. http://dx.doi.org/10.1016/j. prevetmed.2005.02.002. PMid:15907574.

Rousing T, Bonde M, Sørensen JT,. Aggregating welfare indicators into an operational welfare assessment system: a bottom-up approach. Acta Agric Scand A Anim Sci. 2001;51(sup030):537. http://dx.doi.org/10.1080/090647001300004790.

Rudman R. The social organisation of feral donkeys (Equus asinus) on a small Caribbean island (St. John, US Virgin Islands). Appl Anim Behav Sci. 1998;60(2-3):211-28. http:// dx.doi.org/10.1016/S0168-1591(98)00165-8.

Statistical Analysis System Institute - SAS/STAT. Guide of personal computers. Version 9.4. Cary: SAS; 2013.

Waters A. Donkeys: dying for their skin. Vet Rec. 2019;185(23):709. http://dx.doi.org/10.1136/vr.16933. PMid:31831678.

Williams P, Barrif J. Equine sun-induced dermatoses. Vet Nurs. 2011;2(5):248-51. http://dx.doi.org/10.12968/ vetn.2011.2.5.248.

Financial Support: The current study was partially sponsored by The Donkey Sanctuary. 